\title{
Prevalence and Risk Factors for Gallstone Disease in Hail Region
}

Saleh Muflih Alghaythi, Jaber Hathloul Alshammri, Fouad Taiwilaa Alshammari, Fayez Nashi Alshammari, Abdulrahman Yousef Al-Muzaini, Meshari Sultan Turki Alsudayri, Aqeel Jazaa Alshammari University of Hail ABSTRACT

Corresponding Author: Saleh MuflihAlghaythi,+966508073018,email: q1pe54@gmail.com

\begin{abstract}
Aim of the work: this study was carried out to determine the prevalence and risk factors of the occurrence of gallstone disease among the Saudi Arabian population. Patients and methods: a retrospective survey was done among 100 patients with gallstone disease from November 2016 to March 2017 using a structured data collection tool. Results: The results showed that $60 \%$ of those with the disease were women, while only $40 \%$ were men and $29 \%$ belonged to age group 30-39 years old. Among the risk factors studied, there was a statistically significant association between the disease and fever and lipid profile, total cholesterol, LDL, and TAG ( $p$-value, <.01). In addition to fever, majority of the patients also complained for right upper quadrant pain. Perhaps primary health care physicians should consider fever with right upper quadrant pain as warning signs for gallstone disease which should warrant more sensitive procedures like ultrasonography for early detection of the disease. Fundamental knowledge of gallstone disease is essential for clinicians so as proper management be offered to ailing patients.
\end{abstract}

Keywords: gallstone disease, cholelithiasis, cholecystectomy.

\section{INTRODUCTION}

Gallstone disease or cholelithiasis is prevalent worldwide and is a major cause of morbidity and sometimes mortality among the affected individuals. A study in Western countries revealed that the prevalence of gallstone disease reportedly ranged from approximately $7.9 \%$ in men to $16.6 \%$ in women ${ }^{(\mathbf{1})}$.In Asians it ranged from approximately $3 \%$ to $15 \%$, it is nearly non-existent among Africans (less than 5\%) and ranged from $4.21 \%$ to $11 \%$ in $\mathrm{China}^{(2)}$. Gallstone disease became increasingly prevalent in Saudi Arabia, where cholecystectomy was among the most common abdominal operations ${ }^{(3)}$.A study in Asir Region, KSA documented 320 cholecystectomy procedures per year which only reflected the magnitude of symptomatic gallstone disease cases in this region ${ }^{(4)}$.

In other reports, more than $70 \%$ of individuals had asymptomatic gallstone disease ${ }^{(5,6)}$.From a medical economic perspective, gallstone disease was among the most common reason for hospitalization ${ }^{(7)}$.Many studies reported that gallstone disease was related to age, sex and metabolic disorders, such as obesity, dydlipidemiaand type 2 diabetes ${ }^{(8-10)}$.

A study among female teachers in Northern Jordan revealed that gallstone disease was positively associated with age and body mass index (BMI) ${ }^{(11)}$.The pathogenesis of gallstone disease was suggested to be multifactorial and probably developed from complex interactions between many genetic and environmental factors ${ }^{(12,13)}$. With the change in lifestyle such as the Westernization of dietary habits and a decrease in physical activity among Saudis in recent years, it can be suggested that gallstone disease is of increasing health importance. There is scarcity of studies on the prevalence of gallstone at a community level in Saudi Arabia. Looking at the public health standpoint, it is not only important to study the background prevalence of gallstone disease, but also to explore the demographic and biological markers related to its development. As gallstone disease can result in serious outcomes, such as acute gallstone pancreatitis and gallbladder cancer, knowing the factors that can contribute to its development may help people to modify their lifestyle and other relevant activities. Hence, this study was carried out to determine the prevalence of the disease among the Saudi population and to explore the potential risk factors for gallstone disease and to improve the understanding of the overall pathogenesis of this disease.

\section{METHODS}

This study utilized a retrospective study design where data of patients with diagnosed gallstone were extracted and collated using the structured data collection tool. A total of 100 cases were reviewed during the months of November 2016 to March 2017.

The study was done after approval of ethical board of Hail university.

\section{RESULTS}

Table 1 summarized the demographic characteristics of the patients with gallstones. Sixty percent $(60 \%)$ were females, while the remainder (40\%) were males; $28 \%$ belongedto age-group 30 to $39,23 \%$ belonged to age-group $40-49$; $98 \%$ were Saudis and $88 \%$ were married. 
Prevalence and Risk Factors for Gallstone Disease...

Table 1. Demographic characteristics of the patients diagnosed with gallstones $(n=100)$

\begin{tabular}{lrcc}
\hline \multirow{2}{*}{ Gender } & Demographic Characteristics & Frequency & Percentage \\
Age & Male & 40 & $40 \%$ \\
& Female & 60 & $60 \%$ \\
& $19-29$ yrs old & 18 & $18 \%$ \\
& $30-39$ yrs old & 28 & $28 \%$ \\
Nationality & $40-49$ yrs old & 23 & $23 \%$ \\
& $50-59$ yrs old & 18 & $18 \%$ \\
\multirow{3}{*}{ Marital status } & $>60$ yrs old & 12 & $12 \%$ \\
& Saudi & 98 & $98 \%$ \\
& Ethubian & 1 & $1 \%$ \\
& Yemeni & 1 & $88 \%$ \\
\hline
\end{tabular}

Table 2 presented the distribution of gallstone cases of the participants against the identified risk factors. It was evident that 35\% has a normal body mass index (BMI, $20.1-25$ ); $31 \%$ made carbohydrate as a major constituent of their diet, while caffeine was claimed by $25 \%$ of the participants. It is significant to note that nearly $46 \%$ of the patients had family history of gallstones, $19 \%$ were diagnosed to have type 2 diabetes and none of the patients had been diagnosed with liver, chron and hemolysis. The table also showed that $40 \%$ had sedentary life style, $19 \%$ are taking prescribed medications, $15 \%$ had previous similar condition and $13 \%$ either smoke or took alcohol.

Table 2. Distribution of gallstone cases across risk factors (n=99)

\begin{tabular}{|l|r|r|c|}
\hline \multicolumn{2}{|c}{ Risk Factors } & Frequency & Percentage \\
& Body mass index (BMI) & & $5 \%$ \\
& 0 to 20 & 5 & $35 \%$ \\
& 20.1 to 25 & 35 & $25 \%$ \\
& 25.1 to 29.4 & 25 & $31 \%$ \\
& 30.1 to 39.9 & 31 & $3 \%$ \\
\hline Diet & 41.4 to 58.8 & 3 & $23 \%$ \\
& Fatty Meals & 23 & $33 \%$ \\
& Carbohydrates & 33 & $15 \%$ \\
& Salad & 15 & $4 \%$ \\
& Low Fiber & 4 & $25 \%$ \\
\hline Family History & Caffeine & 25 & $46 \%$ \\
& Yes & 46 & $54 \%$ \\
\hline Chronic Diseases & No & 53 & $19 \%$ \\
Diabetes Type 2 & & & $81 \%$ \\
Liver Diseases & Yes & 19 & $0 \%$ \\
Chron's Disease & No & 80 & $100 \%$ \\
Hemolysis & Yes & 0 & $0 \%$ \\
& No & 99 & $100 \%$ \\
\hline Sedentary Life Style & Yes & 0 & $0 \%$ \\
& No & 99 & $100 \%$ \\
\hline Drugs & Yes & 0 & $40 \%$ \\
& No & 99 & $60 \%$ \\
\hline Previous & Yes & 39 & $19 \%$ \\
condition & No & 60 & $81 \%$ \\
\hline Smoking/ Alcohol & Yes & 19 & $15 \%$ \\
& No & 80 & $85 \%$ \\
\hline & Yes & 15 & $87 \%$ \\
\hline
\end{tabular}


Table 3 showed the laboratory results of patients associated with cholecystitis. As can be seen from the table, fever was significantly correlated with cholecystitis $(\mathrm{p}=0.001)$. All other laboratory results revealed no significant relationship with cholecystitis.

Table 3. Correlations between cholecystitis and patient's laboratory results $(n=99)$

\begin{tabular}{lcccc} 
Laboratory Results & Median & Mean & SD & p-value \\
\hline Fever & & & & $.001^{*}$ \\
Lipid Profile & & & & \\
$\quad$ Total cholesterol & 4.4 & 4.9 & 0.7 & .123 \\
$\quad$ HDL & 1.5 & 1.5 & 0.2 & .958 \\
$\quad$ TAG & 1.3 & 1.6 & 0.4 & .107 \\
$\quad$ LDL & 3.1 & 3.3 & 0.5 & .613 \\
Electrolytes & 131 & 138 & 3.5 & .875 \\
$\mathrm{Na}^{+}$ & 4.0 & 4.2 & 0.4 & .583 \\
$\mathrm{~K}^{+}$ & 13 & 13 & 2 & .462 \\
$\mathrm{Hb}$ & 9 & 9 & 2 & .172 \\
$\mathrm{WBC}$ & 6 & 6 & 1.4 & \\
$\mathrm{HbA1c}$ & 4.8 & 4.7 & .6 & \\
$\mathrm{RBC}$ & & & & \\
\hline
\end{tabular}

Table 4 revealed that using t-test for equality of means, there was no significant difference of the occurrence of gallstones between the male and female participants with a p-value of .057 (p>.05).

Table 4. Significant difference on the body mass index (BMI) of the participants as to gender (n=100)

\begin{tabular}{lcccc}
\hline Gender & Occurrence & Mean Difference & t- values & p-value \\
\hline Male & $40 \%$ & -.12956 & 1.081 & .057 \\
Female & $60 \%$ & & & \\
\hline
\end{tabular}

\section{DISCUSSION}

Gallstone disease continued to increase globally making it one of the most common reasons for admission in hospitals which impacted public health in general. In Saudi Arabia, cholecystectomy was one of the most common abdominal operations in general surgical units. A study in Abha City revealed that cholecystectomy constitute about $47 \%$ of major and $23 \%$ of total general surgical operations ${ }^{(4)}$ and about $15 \%-50 \%$ of all laparotomies in 2 different studies in Medina City ${ }^{(5,15)}$.These data only suggested that gallstone disease was really common among the Saudi Arabian population.

In this current investigation, occurrence of gallstone disease among the participants was $60 \%$ in females and only $40 \%$ in males. In congruence with the findings of previous studies, female sex hormone was also a major risk factor which may be attributed to extraneous risk factors such as pregnancy and sex hormones. The number of deliveries seemingly was the most relevant factor as it increased levels of the female hormones which increased biliary cholesterol secretion causing cholesterol super saturation of bile, consequently causing gallstone disease ${ }^{(7)}$.

The findings of this study also revealed that $29 \%$ of the cases occurredin age group 30-39 years old. Many studies revealed that age and gender are among the risk factors for gallstone disease ${ }^{(8-}$ ${ }^{10)}$.However, our result is not conformed with reports from Western countries and other regions of Asia, where older age has higher cases of gallstone disease ${ }^{(15-17)}$.This may be explained on the possibility of long-term exposure to many risk factors among the elderly which increased the risk of gallstone disease such as sedentary lifestyle.

Our findings also revealed that majority of the participants with gallstone has a BMI of 20.1 to 
25 (interpreted as healthy on BMI scale), with no family history of gallstone disease, with no diabetes mellitus, no liver disease, no sedentary lifestyle, no hemolysis, no Chron's disease, and were nonsmokers. Interestingly, many published studies reported that these are risk factors of gallstone disease ${ }^{(8-13)}$.A study in China documented a positive association between DM and gallstone disease in men, but not in women ${ }^{(7)}$.This is inconsistent with the finding of a study in Italy where they found no significant relation between DM and the disease in

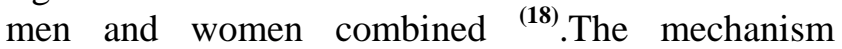
underlying the association of DM with gallstone disease may be fasting hyperinsulinemia, which can overly activate the rate-limiting enzyme for cholesterol synthesis ${ }^{(19)}$ leading to cholesterol saturation in the bile.

In our study, there is no significant difference on the BMI value of the male and female participants which may mean that they belong to a similar population. Previous studies have found positive correlation of BMI with gallstone disease in women,

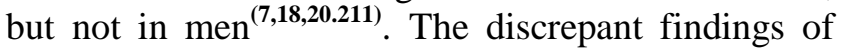
men with gallstone disease have not been fully explained though. The China study pointed out that a possible reason for this observation was that BMI was not a suitable standard of obesity in men ${ }^{(7)}$.It is believed that obese persons may have increased bile saturation resulting from an increase in the biliary secretion of cholesterol which likely was a result of the perceived higher synthesis rate of cholesterol among obese persons ${ }^{(22)}$.

This retrospective study also reviewed the lipid profile, electrolytes, hemoglobin, temperature, site of pain and even WBC and RBC counts of the participants. It is noteworthy that majority of results of the participants fall within the normal range, or near the borderline. Moreover, majority complained a right upper quadrant pain. This study also found a significant relationship between the occurrence of gallstone disease and fever, total cholesterol, LDL, and TAG (p-value< .01, 99\% confidence level), while no significant association was found in other blood analytes. These findings are in accordance with many published studies which showed a positive correlation between the lipid profile of the participants and the occurrence of gallstone disease (22) , however, it deviated from the findings of the study in China ${ }^{(7)}$ which reported otherwise.

Discrepancies of our findings with those published may be attributed to the potential self-selection bias as data were only retrieved from the hospital that was not a representative of the general population of Saudi Arabia or even the region, but we firmly believed that our data can be a starting point to launch a large-scale study involving all regions of Saudi.

\section{CONCLUSION}

In conclusion, gallstone disease was more prevalent in women that in men and majority of those who have the disease belong to age group 30-39 years old (generally a young population). There was significant association between gallstone disease and fever and lipid profile. Perhaps primary health care physicians should consider fever with right upper quadrant pain as warning signs for gallstone disease which should warrant more sensitive procedures like ultrasonography for early detection of the disease. Fundamental knowledge of gallstone disease is essential for clinicians so as proper management be offered to ailing patients.

\section{REFERENCES}

\section{Everhart JE, Khare M, Hill M and Maurer KR} (1999): Prevalence and ethnic differences in gallbladder disease in the United States. Gastroenterology,117: 632639.

2. Xu P, Yin XM, Zhang $M$ and Liang $Y$ (2004): Epidemiology of gallstone in Nanjing City in China. ZhonghuaLiuxingbingxueZazhi,25: 928-933.

3. Tamimi TM, Wosornu L, Abdul-Ghani A and AIKhozaim A (1990): Increased cholecystectomy rates in Saudi Arabia. The Lancet,336(8725):1235-7.

4. Abu-Eshy SA, Mahfouz AA, Badr A, El Gamal MN, Al-Shehri MY,Salati MI andRabie ME (2007):

Prevalence and risk factors of gallstone disease in a high altitude Saudi population. Eastern Mediterranean Health Journal, 13(4):794-802.

5. Ahmed AF, El-Hassan OM and Mahmoud ME (1992): Risk factors for gallstone formation in young Saudi women: a case control study. Annals of Saudi medicine, 12 (4): 395-9.

6. Hopper KD , Landis JR, Meilstrup JW, McCauslin MA and Sechtin AG (1991): The prevalence of aymptomatic gallstones in the general population. Investigative radiology, 26(11):939-45.

7. Sun H, Tang H, Jiang S, Zeng L, Chen EQ, Zhou TY and Wang YJ (2009): Gender and metabolic differences of gallstone diseases. World journal of gastroenterology: WJG., 15(15):1886.

8. Katsika D, Tuvblad C, Einarsson C, Lichtenstein P and Marschall HU (2007): Body mass index, alcohol, tobacco and symptomatic gallstone disease: a Swedish twin study. J Intern Med., 262: 581-587

9. Tsai CJ, Leitzmann MF, Willett WC and 
Giovannucci EL (2006): Weight cycling and risk of gallstone disease in men. Arch Intern Med., 166: 23692374

10.Park YH, Park SJ, Jang JY, Ahn YJ, Park YC, Yoon YB and Kim SW (2004): Changing patterns of gallstone disease in Korea. World J Surg.,28: 206-210

11.Jaddou HY, Ammari FF, Shreideh M, Ababneh K (1996): Prevalence and risk factors of gallstone disease among female teachers in Northern Jordan. Saudi medical journal, 17(2):137-44

12. Marschall HU and Einarsson C (2007): Gallstone disease. J Intern Med .,261: 529-542

13. Méndez-Sánchez N, Chavez-Tapia NC and Uribe M (2003): The role of dietary fats in the pathogenesis of gallstones. Front Biosci8: e420-e427.

14.Ahmed AF et al. (1993): Gallstones revisited AlmadinahAlmounawarah's experience (a prospective study of 212 consecutive cases). Saudi medical journal, 14(5):436-9.

15. Kono S, Shinchi K, Ikeda N, Yanai F and Imanishi K (1992):Prevalence of gallstone disease in relation to smoking, alcohol use, obesity, and glucose tolerance: a study of self-defense officials in Japan. Am J Epidemiol.,136: 787-794

16.Lu SN, Chang WY, Wang LY, Hsieh MY, Chuang WL, Chen SC, Su WP, Tai TY, Wu MM and Chen CJ (1990): Risk factors for gallstones among Chinese in Taiwan. A community sonographic survey. $J$
ClinGastroenterol.,12: 542-546

17. Festi D, Dormi A, Capodicasa S, Staniscia T, Attili AF, LoriaP ,Pazzi P, Mazzella G, Sama C, Roda E and Colecchia A (2008): Incidence of gallstone disease in Italy: Results from a multicenter, population-based Italian study (the MICOL project). World J

Gastroenterol.,14: 5282-5289

18. Barbara L, Sama C, MorselliLabate AM, Taroni F, Rusticali AG, Festi D, Sapio C, Roda E, Banterle C and Puci A (1987): population study on the prevalence of gallstone disease: the Sirmione Study. Hepatology, 7: 913-917.

19. Graewin SJ, Kiely JM, Lee KH, Svatek CL, Nakeeb A and Pitt HA (2004): Nonobese diabetic mice have diminished gallbladder motility and shortened crystal observation time. J GastrointestSurg.,8: 824-829.

20.Jørgensen T (1989): Gall stones in a Danish population. Relation to weight, physical activity, smoking, coffee consumption, and diabetes mellitus. Gut, 30: 528-534.

21. The Rome Group for Epidemiology and Prevention of Cholelithiasis (GREPCO) (1988): The epidemiology of gallstone disease in Rome, Italy. Part II. Factors associated with the disease. Hepatology, 8: 907-913.

22. Liu CM, Tung TH, Liu JH, Lee WL and Chou P. A (2004): community- based epidemiologic study on gallstone disease among type 2 diabetics in Kinmen, Taiwan. Dig Dis .,22: 87-91. 